\title{
Doses de dejeto líquido de suínos na comunidade da fauna edáfica em sistema plantio direto e cultivo mínimo
}

\author{
Doses of liquid swine slurry on soil biota community under no tillage and minimum tillage
}

\author{
Rodrigo Ferreira da Silva ${ }^{\mathrm{I}^{*}}$ Gilvan Moisés Bertollo ${ }^{\mathrm{II}}$ Geomar Mateus Corassa ${ }^{\mathrm{II}}$ \\ Leonardo Burin Cocco ${ }^{\mathrm{III}}$ Ricardo Bemfica Steffen ${ }^{\mathrm{IV}}$ Claudir José Basso ${ }^{\mathrm{I}}$
}

\section{RESUMO}

A elevada produção de dejeto líquido de suínos faz do solo a principal alternativa para a sua utilização na forma de fertilizante orgânico. Contudo, a adição de resíduos orgânicos nos sistemas de manejo do solo é um fator que pode influenciar a biota do solo. O objetivo deste trabalho foi avaliar a influencia da aplicação de doses de dejeto líquido de suíno na fauna do solo em diferentes sistemas de cultivos. O trabalho foi desenvolvido em área experimental no município de Taquaruçu do Sul, RS. O delineamento foi em blocos casualisados em arranjo fatorial (2x5), sendo dois sistemas de manejo do solo (mínimo e plantio direto) e cinco doses $\left(0,20,40,80 \mathrm{~m}^{3} \mathrm{ha}^{-1}\right.$ de dejeto líquido de suíno e adubação química) com quatro repetições. As coletas da fauna edáfica foram realizadas com armadilhas tipo PROVID, em parcelas de 22,5m². Avaliou-se o total de grupos, colêmbolos, ácaros, abundância, riqueza, índice dominância de Simpson, diversidade de Shannon e o índice de Pielou. Os resultados indicam que o sistema plantio direto associado a 40 e $80 \mathrm{~m}^{3} \mathrm{ha}^{-1}$ resultam em maior abundância de organismos, ocasionada pelo maior número de colêmbolos. A população de ácaros é maior no cultivo mínimo, em comparação ao sistema plantio direto na dose de $80 \mathrm{~m}^{3} \mathrm{ha}^{-1}$. No sistema plantio direto, a dominância de Simpson aumenta e a diversidade de Shannon diminui com a elevação das doses de dejeto líquido de suíno.

Palavras-chave: artrópodes do solo, adubação orgânica, sistemas de manejo do solo.

\section{ABSTRACT}

The high production of liquid pig slurry makes the soil, the main alternative to its use as an organic fertilizer. However, the addition of organic residues in soil management systems is a factor that may influence the soil biota. The aim of this study was to evaluate the influence of dose application of liquid swine manure on soil biota in different cropping systems. The study was conducted in the experimental area located in the Taquaruçu do Sul. The design was a randomized block factorial arrangement (2x5), two soil management (minimum and no tillage) and five doses $\left(0,20,40,80 \mathrm{~m}^{3} \mathrm{ha}^{-1}\right.$ of liquid swine slurry and chemical fertilizer - ROLAS) with four replications. Sampling of soil biota was carried out with PROVID traps in plots of $22.5 \mathrm{~m}^{2}$. It was evaluated the total group, springtails, mites, abundance, richness, Simpson's index, Shannon's diversity and Pielou's index. The results indicate that no tillage system associated with 40 and $80 \mathrm{~m}^{3} \mathrm{ha}^{-1}$ resulted in a greater abundance of organisms, caused by the greater number of springtails. The mite population is larger in minimum tillage compared to no tillage at a rate of $80 \mathrm{~m}^{3} \mathrm{ha}^{-1}$. In notillage increases the dominance of Simpson and Shannon diversity decreases with increasing levels of liquid swine manure.

Keywords: soil arthropods, organic fertilizer, soil management systems.

\section{INTRODUÇÃO}

A suinocultura constitui uma das principais atividades zootécnicas com potencial econômico em diversas regiões agrícolas do Sul do Brasil (AITA et al., 2006). Nos últimos anos, tem-se observado aumento significativo da produção de suínos, e esse incremento no número de animais resulta em maior produção de dejeto líquido de suínos (DSL) nos confinamentos, resultando como principal alternativa ao produtor a utilização desse resíduo como adubo orgânico.

IDepartamento de Ciências Agronômicas e Ambientais, Universidade Federal de Santa Maria (UFSM), Campus de Frederico Westphalen, 98400-000, Frederico Westphalen, RS, Brasil. E-mail: rodrigosilva@smail.ufsm.br.*Autor para correspondência.

IIPrograma de Pós-graduação em Agronomia, Agricultura e Ambiente, UFSM, Campus de Frederico Westphalen, Frederico Westphalen, RS, Brasil.

IIIAutônomo, Júlio de Castilhos, RS, Brasil.

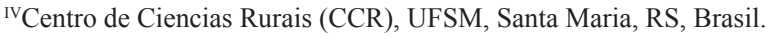


Na maioria dos trabalhos que envolveram o uso desse material orgânico no cultivo de milho, tem-se observado aumento significativo na produtividade de grãos da cultura (GIACOMINI \& AITA, 2008). COSTA et al. (2011) relataram que a utilização de resíduos de animais, associada ao uso de plantas de cobertura, promove uma sincronização entre a mineralização e a demanda de nutrientes pelas culturas, contribuindo, assim, para a melhoria da produtividade. A utilização continuada de DLS como fertilizante em áreas com culturas anuais proporciona maior acúmulo de nutrientes $(\mathrm{P}, \mathrm{K}, \mathrm{Cu}$ e $\mathrm{Zn}$ ) na camada superficial do solo do que a adubação mineral (SCHERER et al., 2010). Além disso, os DSL são ricos em $\mathrm{N}$ amoniacal e, quando aplicados sobre resíduos culturais com elevada relação $\mathrm{C} / \mathrm{N}$, como os de cereais, poderão aumentar a velocidade de decomposição deles no solo (RECOUS et al., 1995).

Alterações na fauna edáfica podem ocorrer em função do uso da terra, de modificações no ambiente, do preparo e cultivo do solo e da adição de matéria orgânica (BARETTA et al., 2007). Segundo SILVA et al. (2006), a comunidade da macrofauna edáfica é um parâmetro sensível ao impacto de diferentes tipos de sistemas de produção, o que possibilita seu uso como instrumento na determinação de opções de manejo dos sistemas agropecuários. $\mathrm{O}$ conhecimento dos grupos funcionais da macrofauna do solo pode fornecer informações sobre o impacto gerado no solo, a partir da exclusão de um ou mais organismos edáficos (BARETTA et al., 2007). Entretanto, são escassos os estudos referentes à influencia da aplicação de DLS sobre a comunidade da fauna edáfica.

No que se refere a grupos funcionais da fauna do solo, ácaros e colêmbolos são considerados indicadores das condições biológicas do solo, por causa da sua sensibilidade às condições ambientais e alterações antrópicas impostas ao solo (DAMÉ et al., 1996; BARETTA et al., 2008). Associado a isso, a habilidade manifestada pelos organismos da fauna edáfica para integrar propriedades físicas, químicas e biológicas do ecossistema os tornaram um potencial bioindicador da qualidade do solo (DORAN \& ZEISS, 2000). Desse modo, grupos específicos da fauna edáfica, como ácaros e colêmbolos poderão ser utilizados para avaliar modificações no solo, impostas pelos sistemas de manejo. O trabalho teve o objetivo de avaliar a influencia da aplicação de doses de DLS na comunidade da fauna do solo em diferentes sistemas de manejo do solo.

\section{MATERIAL E MÉTODOS}

O trabalho foi desenvolvido em uma área experimental no município de Taquaruçu do Sul (RS), localizado na latitude $27^{\circ} 23^{\prime} 45,75^{\prime}$ S e longitude $53^{\circ} 25^{\prime} 45,92^{\prime \prime} \mathrm{O}$, estando a uma altitude aproximada de 475 metros. O solo é classificado como um Latossolo Vermelho distrófico típico (EMBRAPA, 1999), sendo explorado com culturas anuais. A análise do solo, seguindo metodologia da EMBRAPA (1997), apresentou as seguintes características físicoquímicas: $29 \%$ de argila; $5,6 \mathrm{pH} \mathrm{H}_{2} \mathrm{O} ; 2,2 \mathrm{mg} \mathrm{dm}^{-3} \mathrm{de}$ $\mathrm{P}$ (Mehlich-1); 0,17 $\mathrm{cmol}_{\mathrm{c}} \mathrm{dm}^{-3}$ de K; 10,1 $\mathrm{cmol}_{\mathrm{c}} \mathrm{dm}^{-3}$ de $\mathrm{Ca}^{2+} ; 3,0 \mathrm{cmol}_{\mathrm{c}} \mathrm{dm}^{-3}$ de $\mathrm{Mg}^{2+}$ e 2,3\% de matéria orgânica. $\mathrm{O}$ relevo é levemente ondulado e o clima da região, segundo Köppen, é do tipo $\mathrm{Cfa}$, com temperatura média anual de $19^{\circ} \mathrm{C}$ e precipitação de 1.800 a $2.000 \mathrm{~mm}$ bem distribuídos ao longo do ano.

Para o trabalho, utilizou-se um experimento que vem sendo conduzido há dois anos, com o objetivo de avaliar o efeito da aplicação de DLS e do manejo de solo sobre a produção de biomassa da aveia preta e produtividade do milho. Durante os dois anos de condução do experimento em sucessão aveia preta/milho, foram aplicados, em diferentes parcelas, 0, 20, 40 e $80 \mathrm{~m}^{3} \mathrm{ha}^{-1}$ de DLS, antecedendo em cinco dias o estabelecimento da aveia preta e do milho, enquanto que a adubação química (SBCS, 2004) só foi utilizada na cultura do milho. Dessa forma, já haviam sido realizadas três aplicações de DLS das respectivas doses na área experimental.

O levantamento da fauna edáfica foi realizado em parcelas de $22,5 \mathrm{~m}^{2}$. O delineamento foi o de blocos casualizados, em arranjo fatorial $2 \times 5$, com dois sistemas de manejo do solo (mínimo e plantio direto) e cinco doses $\left(0,20,40\right.$ e $80 \mathrm{~m}^{3} \mathrm{ha}^{-1}$ de DLS e adubação química (SBCS, 2004)) com quatro repetições. A instalação das armadilhas do tipo PROVID (ANTONIOLLI et al., 2006) ocorreu no dia 7 de julho de 2010 quando a cultura de aveia preta, implantada sobre restos culturais de milho, apresentava-se com 7 a 8 folhas. As armadilhas permaneceram instaladas nos tratamentos por sete dias, contendo em seu interior $200 \mathrm{ml}$ de álcool $70 \%$ para conservação dos indivíduos capturados. Os indivíduos extraídos nas armadilhas foram identificados quanto à classe ou ordem, com auxílio de lupas binoculares, com aumento de 60 vezes.

A partir da contagem e identificação em nível de grupo (classe/ordem) dos organismos edáficos, foram calculados os seguintes índices de biodiversidade: índice de riqueza de Margalef, dado por $\mathrm{I}=[(\mathrm{n}-1)] / \mathrm{ln} \mathrm{N}$, em que I é a diversidade, $\mathrm{n}$ é o 
número de espécies presente e $\mathrm{N}$ é o número total de indivíduos encontrados na amostra; índice de Simpson, forma de dominância dada por $\mathrm{S}=\sum(\mathrm{ni} / \mathrm{N})^{2}$, sendo ni = número indivíduos do grupo "i”, $\mathrm{N}$ o somatório da densidade de todos os grupos; (3) índice de Diversidade de Shannon $\left(\mathrm{H}=-\sum P i \log P i\right.$, em que $P i$ é a proporção do grupo $i$ no total da amostra; e (4) índice de equabilidade de Pielou definido por: $\mathrm{e}=\mathrm{H} /$ Log S, em que H corresponde ao índice de Shannon e $\mathrm{S}$ é o número total de grupos na comunidade, conforme ODUM (1986). A riqueza dos grupos taxonômicos foi indicada pelo número de grupos presentes no tratamento.

O estudo da relação entre a distribuição de indivíduos de cada grupo taxonômico, os tratamentos de manejo do solo e adubação foram realizados por meio de uma ordenação gerada pela análise de correlação canônica (CCA), utilizando-se o software CANOCO, Versão 4.0 (TER BRAAK \& SMILAUER, 1998). Os dados de contagem obtidos foram submetidos à transformação $(X+0,5)^{0,5}$ e os parâmetros determinados foram submetidos ao teste F. Após, para os efeitos significativos, as médias foram comparadas pelo teste de Tukey em nível de 5\% de significância, utilizando-se o programa estatístico SISVAR (FERREIRA, 2008).

\section{RESULTADOS E DISCUSSÃO}

Os resultados da coleta revelaram a presença de indivíduos da fauna do solo, distribuídos em oito diferentes grupos, sendo: acarina, aranae, collembola, coleóptera, díptera, hemiptera, hymenoptera, larvas e oligoquetas (Tabela 1). Verifica-se que, no cultivo mínimo, foram encontrados 1.319 indivíduos e, no sistema plantio direto, 1.271 indivíduos (Tabela 1). Observa-se também que as ordens collembola e acarina foram as mais abundantes, representando, respectivamente, $61,7 \%$ e $29,2 \%$ do total de indivíduos no cultivo mínimo e $77,7 \%$ e $12 \%$ no plantio direto. Segundo DAMÉ et al. (1996), ácaros e collêmbolos são os indivíduos mais abundantes da mesofauna e servem como indicadores das condições biológicas do solo, devido às suas sensibilidades às condições ambientais.

Tabela 1 - Número de indivíduos, total, frequência relativa e identificação dos grupos (classe/ordem) coletados nas doses $0,20,40$ e $80 \mathrm{~m}^{3}$ ha ${ }^{-1}$ de DSL e adubação química nos sistemas de manejo do solo cultivo mínimo (CM) e plantio direto (PD). UFSM, Frederico Westphalen, 2011.

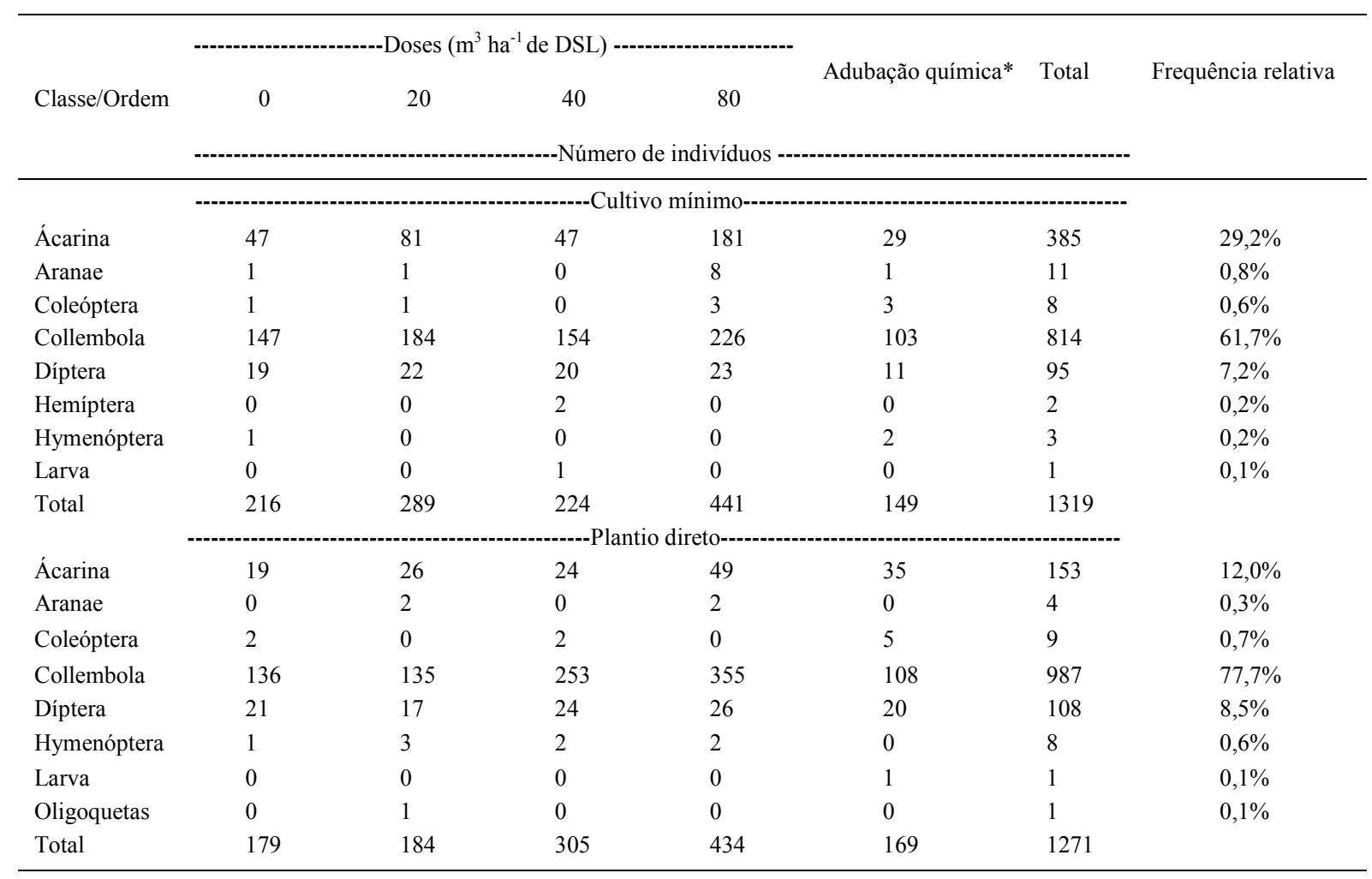

* conforme recomendação da SBCS (2004). 
Não houve interação significativa entre os sistemas de manejo do solo e doses de DLS para população de colêmbolos, contudo, os resultados revelaram que o número de colêmbolos no plantio direto foi maior para a dose de $80 \mathrm{~m}^{3} \mathrm{ha}^{-1}$, diferindo significativamente da adubação mineral (Tabela 2). Esses organismos são considerados bioindicadores de distúrbios, bem como da qualidade do solo, pois sua diversidade e riqueza de famílias são sensíveis às interações antrópicas (BARETTA et al., 2008). Resultados semelhantes também foram obtidos por SAUTER et al. (1996), os quais verificaram que as populações de colêmbolos aumentam com o incremento no teor de matéria orgânica na superfície do solo e ainda por BANDYOPADHYAYA et al. (2002), que, ao estudarem o efeito de alguns fatores físicos e práticas agrícolas em colêmbolos, constataram que a aplicação de dejetos induziu aumento na população desses artrópodes. Isso pode ter ocorrido nesse trabalho devido às sucessivas aplicações de $80 \mathrm{~m}^{3} \mathrm{ha}^{-1}$ de DLS no plantio direto (Tabela 2). Entretanto, o cultivo mínimo não apresentou diferença significativa para os colêmbolos entre as doses de DLS (Tabela 2).

A população de ácaros foi maior sob cultivo mínimo, em comparação ao sistema plantio direto para a dose $80 \mathrm{~m}^{3} \mathrm{ha}^{-1}$ (Tabela 2). Sabe-se que o DLS é rico em $\mathrm{N}$ amoniacal e, quando aplicado sobre resíduos culturais com elevada relação $\mathrm{C} / \mathrm{N}$, pode aumentar a sua velocidade de decomposição no solo, em razão da assimilação de $\mathrm{C}$ pelos microrganismos decompositores ser acompanhada pela assimilação simultânea de N (RECOUS et al., 1995). GIACOMINI et al. (2009), estudando DLS em plantio direto e preparo reduzido do solo, concluíram que o potencial da palha de aveia em causar imobilização do $\mathrm{N}$ amoniacal dos dejetos foi de $4,2 \mathrm{~kg}$ de $\mathrm{N}$ para cada $\mathrm{Mg}$ de $\mathrm{C}$ adicionado com a palha, promovendo, assim, maior disponibilidade de nutrientes no solo com elevadas doses de DLS. Desse modo, supõe-se que a adição de $80 \mathrm{~m}^{3}$ ha ${ }^{-1}$ de DLS esteja proporcionando maior decomposição do resíduo orgânico, pelo ajuste na relação $\mathrm{C} / \mathrm{N}$ e, assim, contribuindo para o aumento de ácaros decompositores do solo.

Houve interação significativa para o índice de Pielou, revelando maior valor nas doses 40 e $80 \mathrm{~m}^{3}$ ha $^{-1}$ no cultivo mínimo em comparação ao plantio direto (Tabela 2). Conforme LIMA et al. (2010), os sistemas de manejo e de preparo do solo afetam a estrutura dos grupos taxonômicos dominantes da macrofauna edáfica. No manejo do solo em plantio direto, após as sucessivas aplicações de dejeto líquido de suínos, as doses de 40 e $80 \mathrm{~m}^{3}$ ha $^{-1}$ apresentaram menor valor para o índice de Pielou (Tabela 2). Essa redução no índice de Pielou pode ter ocorrido pelo aumento da população de colêmbolos nessas doses. O sistema de manejo do solo, as doses de DLS e a adubação química não apresentaram diferença significativa para abundância de indivíduos, total de grupos e riqueza (Tabela 2 ).

Tabela 2 - Abundância de indivíduos, Total de Grupos, Número de colêmbolos e ácaros, Índice uniformidade de Pielou, Riqueza de Margalef, Dominância de Simpson e Diversidade de Shannon nas doses $0,20,40$ e $80 \mathrm{~m}^{3} \mathrm{ha}^{-1}$ de dejeto líquido de suíno e adubação química nos sistemas de manejo do solo cultivo mínimo e plantio direto. Frederico Westphalen, 2011.

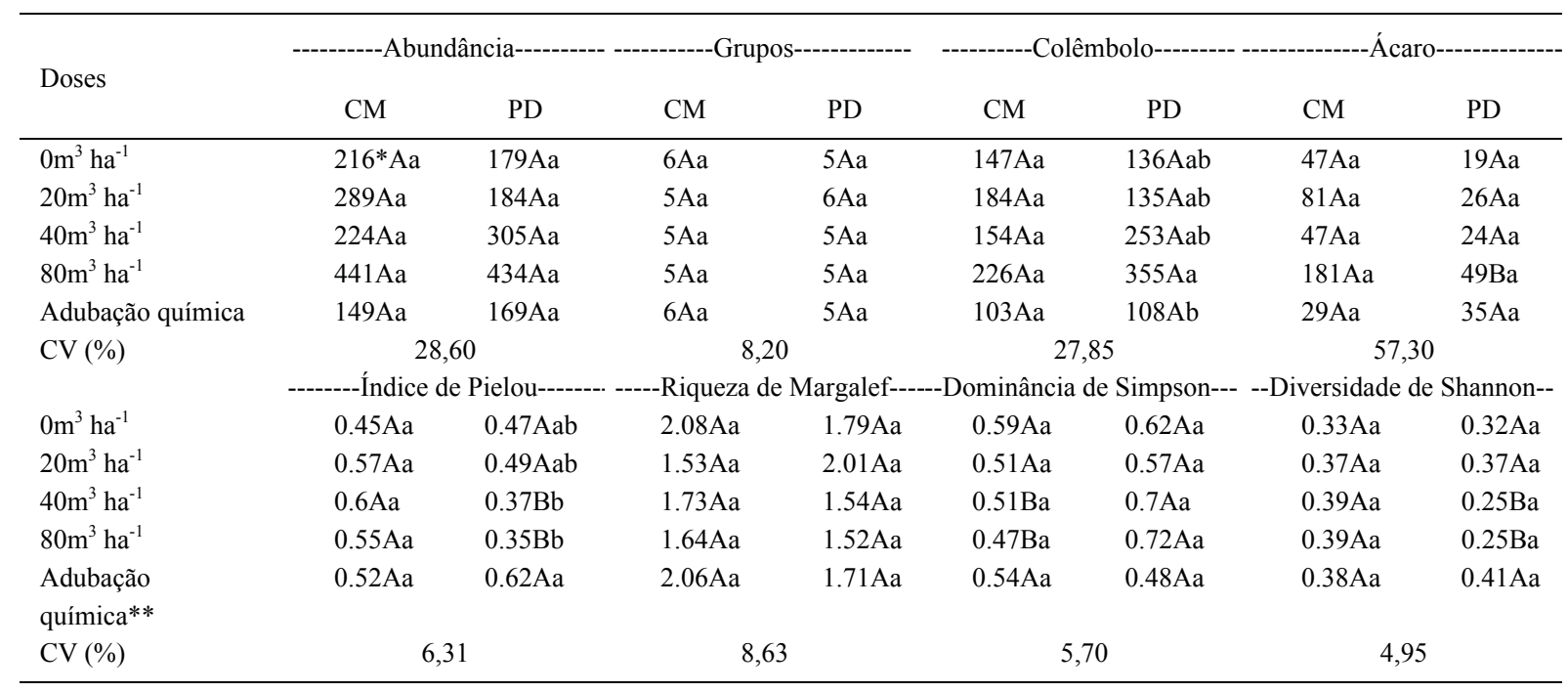

* Médias seguidas de mesma letra minúscula na coluna e maiúscula na linha não diferem entre si pelo teste de Tukey a 5\% de probabilidade.

** conforme recomendação da SBCS (2004). 
O manejo do solo plantio direto apresentou maior dominância de Simpson em relação ao sistema cultivo mínimo, nas doses de 40 e $80 \mathrm{~m}^{3} \mathrm{ha}^{-1}$ de DLS (Tabela 2). A ocorrência de um determinado grupo da fauna edáfica, deve-se ao tipo de preparo do solo e, principalmente, aos efeitos benéficos dos resíduos vegetais mantidos na superfície do solo, que proporcionam ambiente mais favorável para a sobrevivência de determinados grupos (MOÇO et al., 2005). Esse comportamento diferenciado de grupos específicos da fauna do solo, em relação aos sistemas de manejo com $80 \mathrm{~m}^{3}$ ha ${ }^{-1}$ de DLS foi evidenciado pelo aumento na população de colêmbolos em relação às demais doses no sistema plantio direto (Tabela 2), resultando em maior dominância de Simpson nesse manejo do solo. Não houve diferença significativa na dominância de Simpson nas doses testadas (Tabela 2).

A diversidade de Shannon foi maior no cultivo mínimo em relação ao plantio direto nas doses de 40 e $80 \mathrm{~m}^{3}$ ha $^{-1}$ de DLS (Tabela 2). Conforme CHANTIGNY et al. (2001), estudando a incorporação da palha de cereais ao solo, eles observaram que os DLS aumentaram a mineralização do $\mathrm{C}$ da palha, graças ao estímulo proporcionado pelo $\mathrm{N}$ amoniacal dos dejetos sobre a atividade da população microbiana decompositora. Nesse caso, o pequeno revolvimento do solo no cultivo mínimo, associado às elevadas doses de DLS, podem ter alterado a relação $\mathrm{C} / \mathrm{N}$ do resíduo orgânico, contribuindo na digestibilidade do resíduo pelos organismos edáficos e, consequentemente, trazendo maior diversidade da fauna do solo.

O modelo multivariado, utilizado para avaliar a diversidade da fauna edáfica nos diferentes sistemas de manejo do solo, demonstra a variabilidade biológica presente nas áreas estudadas, apresentando relação dos grupos de organismos com as modificações no solo, decorrentes dos manejos do solo (Figura 1), corroborando com os dados descritos na literatura, os quais demonstram a influência do homem nas comunidades e cadeias alimentares de organismos no solo (MOÇO et al., 2005).

De acordo com os resultados, o tratamento plantio direto com 40 e $80 \mathrm{~m}^{3}$ ha $^{-1}$ de DLS resultaram em maior população de colêmbolos, além de apresentar maior dominância e abundância de organismos (Figura 1). Já a maior presença de ácaros foi observada no tratamento cultivo mínimo com 20 e $80 \mathrm{~m}^{3} \mathrm{ha}^{-1}$. O índice de diversidade não apresentou relação direta com os diferentes tipos de manejo do solo (Figura 1). No entanto, o índice apresentou tendência de associação aos tratamentos plantio direto e cultivo mínimo com $40 \mathrm{~m}^{3} \mathrm{ha}^{-1}$ de DLS. Conforme SILVA et al. (2006), o manejo adequado dos cultivos

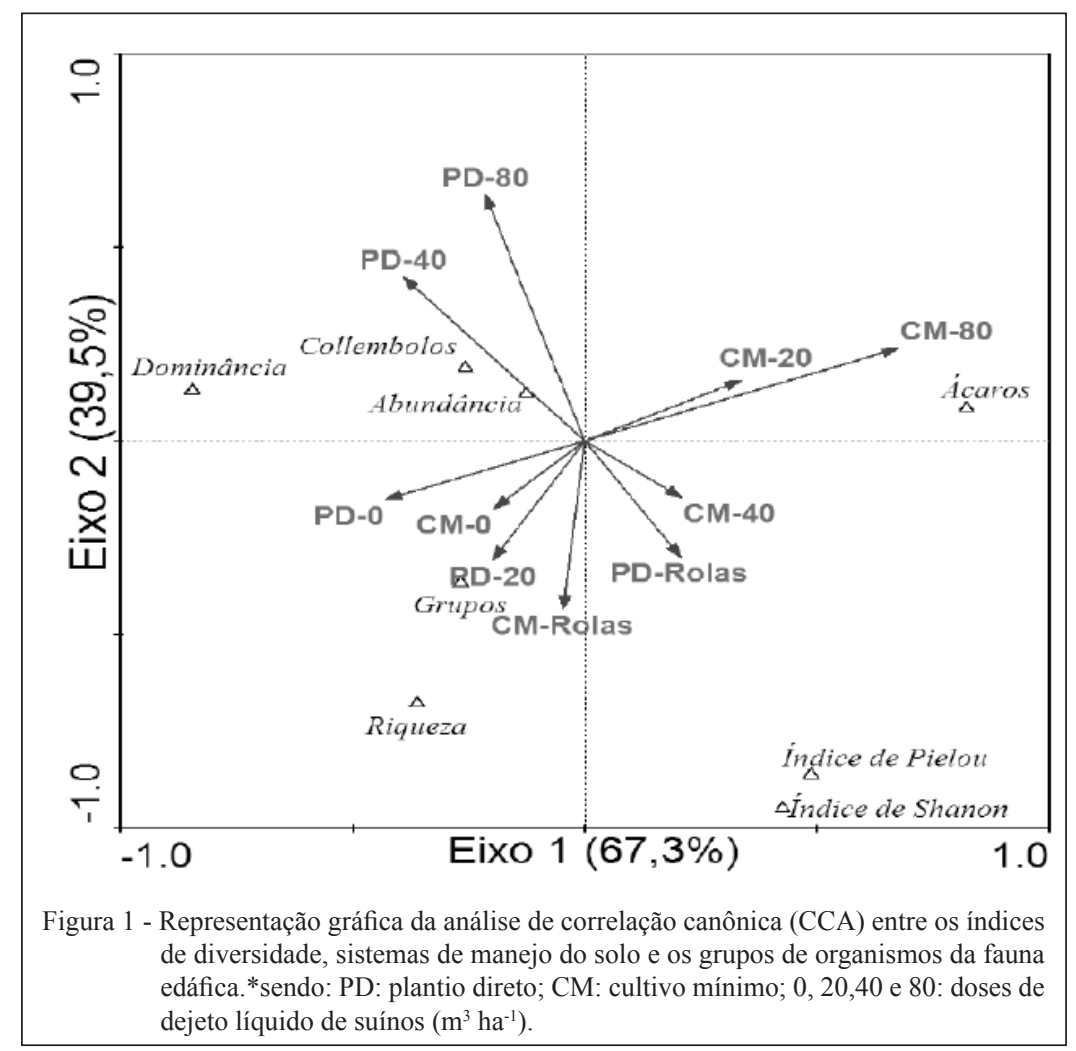

Ciência Rural, v.44, n.3, mar, 2014. 
e a adoção de boas práticas agrícolas favorecem a diversidade da fauna edáfica, pois estimulam a dinâmica da matéria orgânica do solo. BARETTA et al. (2007) obtiveram menor diversidade de fauna com adubação mineral, livre de vegetação.

\section{CONCLUSÃO}

O aumento das doses de dejeto líquido de suínos aumenta o número de Colêmbolos no sistema plantio direto e a população de ácaros é maior no cultivo mínimo em relação ao plantio direto com a elevação das doses de DLS. As doses de 40 e $80 \mathrm{~m}^{3}$ $\mathrm{ha}^{-1}$ de DLS reduzem a diversidade de Shannon e aumentam a dominância de Simpson no sistema plantio direto, em relação ao cultivo mínimo.

\section{REFERÊNCIAS}

AITA, C. et al. Decomposição de palha de aveia preta e dejetos de suínos em solo sob plantio direto. Revista Brasileira de Ciência do Solo, Viçosa, v.30, n.1, p.149-161, 2006. Disponível em: $<$ http://www.scielo.br/scielo.php?script=sci arttext\&pid=S0100$06832006000100015 \& \operatorname{lng}=\mathrm{en}>$. Acesso em: 15 jan. 2012. doi: 10.1590/S0100-06832006000100015

ANTONIOLLI, Z.I. et al. Método alternativo para estudar a fauna do solo. Ciência Florestal, Santa Maria, v.16, n.4, p.407-417, 2006. Disponível em: <http://cascavel.ufsm.br/revistas/ojs-2.2.2/ index.php/cienciaflorestal/article/view/1922/1164>. Acesso em: 17 jan. 2012. ISSN 1980-5098.

BANDYOPADHYAYA, I. et al. Effects of some physical factors and agricultural practices on Collembolla in a multiple cropping programme in west Bengal (India). European Journal Soil Biology, Bengal, v.38, n.1,p.111-117,2002. Disponível em: $<$ http:// www.sciencedirect.com/science/article/pii/S1164556301011141>. Acesso em: 13 jan. 2012. doi: 10.1016/S1164-5563(01)01114-1.

BARETTA, D. et al. Colêmbolos (Hexapoda: Collembola) como bioindicadores de qualidade do solo em áreas com Araucaria angustifólia. Revista Brasileira de Ciência do Solo, Viçosa, v.32, n.spe, p.2693-2699, 2008. Disponível em: <http:// www.scielo.br/scielo.php? script $=$ sci arttext\&pid $=\mathrm{S} 0100$ $06832008000700012 \&$ lang=pt $>$. Acesso em: 31 out. 2012. doi: $10.1590 / \mathrm{S} 0100-06832008000700012$.

BARETTA, D. et al. Earthworm populations sampled using collection methods in Atlantic forests with Araucaria angustifolia Scientia Agricola, Piracicaba, v.64, p.384-392, 2007. Disponível em: <http://www.scielo.br/scielo.php?script=sci arttext\&pid=S0103-90162007000400009\&lng=en $>$. Acesso em: 15 jan. 2012. doi: 10.1590/S0103-90162007000400009.

CHANTIGNY, M.H. et al. Shortterm C and N dynamics in a soi amended with pig slurry and barley straw: A field experiment Canadian Journal of Soil Science, Ottawa, v.81, p.131-137, 2001. Disponivel em: <http://pubs.aic.ca/doi/abs/10.4141/S00046>. Acesso em: 20 jan. 2012. doi: 10.4141/S00-046.
COSTA, M.S.S. de M. et al. Nutrição e produtividade da cultura do milho em sistemas de culturas e fontes de adubação. Revista Ceres, Viçosa, v.58, n.2, p.389-399, 2011. Disponível em: <http://www.scielo.br/scielo.php?pid=S0034737X2011000200018\&script=sci_arttext $>$. Acesso em: $17 \mathrm{jan}$. 2012. doi: 10.1590/S0034-737X2011000200018.

DAMÉ, P.R.V. et al. Efeitos da queimada seguida de pastoreio ou diferimento sobre o resíduo, temperatura do solo e mesofauna de uma pastagem natural. Ciência Rural, Santa Maria, v.26, p.391-396, 1996. Disponível em: <http://www.scielo.br/scielo. php?script $=$ sci arttext\&pid $=$ S0103-84781996000300008\&lng=e $\mathrm{n} \& \mathrm{nrm}=\mathrm{iso} \& \operatorname{lng}=\mathrm{pt}>$. Acesso em: 20 jan. 2012. doi: $10.1590 /$ S0103-84781996000300008.

DORAN, J.W.; ZEISS, M.R. Soil health and sustainability: managing the biotic vompont of soil quality. Applied Soil Ecology, Belfield, n.15, p.3-11, 2000. Disponível em: <http://www. sciencedirect.com/science/article/pii/S0929139300000676\#>. Acesso em: 31 out. 2012.

EMBRAPA. Centro Nacional de Pesquisa de Solos (Rio de Janeiro, RJ). Manual de métodos de análises de solo. 2.ed. Rio de Janeiro, 1997. 212p.

EMPRESA BRASILEIRA DE PESQUISA AGROPECUÁRIA. Centro Nacional de Pesquisa de Solos. Sistema Brasileiro de Classificação de Solo. Brasília, Embrapa Produção de Informações, 1999. 412p.

FERREIRA, D.F. SISVAR: um programa para análises e ensino de estatística. Revista Symposium, Lavras, v.6, p.36-41, 2008. Disponível em: <http://www.fadminas.org.br/symposium/>. Acesso em: 13 jan. 2012. ISSN 1678-703X

GIACOMINI, S.J. et al. Imobilização do nitrogênio amoniacal de dejetos líquidos de suínos em plantio direto e preparo reduzido do solo. Revista Brasileira de Ciência do Solo, Viçosa, v.33, p.41-50, 2009. Disponível em: $<\mathrm{http}: / / \mathrm{www}$. scielo.br/scielo.php?script=sci arttext\&pid $=\mathrm{S} 0100-06832009000100005 \& \operatorname{lng}=\mathrm{en}>$. Acesso em: 20 jan. 2012. doi: 10.1590/S0100-06832009000100005.

GIACOMINI, S.J.; AITA, C. Cama sobreposta e dejetos líquidos de suínos como fonte de nitrogênio ao milho. Revista Brasileira de Ciência do Solo, Viçosa, v.32, p.195-205, 2008. Disponível em: <http://www.scielo.br/scielo.php?pid=S0100$06832008000100019 \&$ script $=$ sci arttext $>$. Acesso em: 20 jan. 2012. doi: 10.1590/S0100-06832008000100019.

LIMA, S.S. de et al. Relação entre macrofauna edáfica e atributos químicos do solo em diferentes agroecossistemas. Pesquisa Agropecuária Brasileira, Brasília, v.45, n.3, p.322-331, 2010. Disponível em: $\quad<\mathrm{http}$ ://www.scielo.br/scielo.php?script=sci arttext\&pid $=\mathrm{S} 0100-204 \mathrm{X} 2010000300013 \& \operatorname{lng}=\mathrm{en} \& \mathrm{nrm}=$ is o\&tlng=pt $>$. Acesso em: 17 jan. 2012. doi: 10.1590/S0100204X2010000300013.

MOÇO, M.K. et al. Caracterização da fauna edáfica em diferentes coberturas vegetais na região norte fluminense. Revista Brasileira de Ciência do Solo, Viçosa, v.29, p.555-564, 2005. Disponível em: $<$ http://www.scielo.br/scielo.php?script=sci_arttext\&pid=S0100$06832005000400008 \& \operatorname{lng}=\mathrm{en}>$. Acesso em: 17 jan. 2012. doi: 10.1590/S0100-06832005000400008.

ODUM, E.P. Ecologia. Rio de janeiro: Guanabara, 1986. 434p.

Ciência Rural, v.44, n.3, mar, 2014. 
RECOUS, S. et al. Soil inorganic N availability: effect on maize residue decomposition. Soil Biology Biochemistry, Elmsford, v.27, p.1529-1538, 1995. Disponível em: <http:// www.sciencedirect.com/science/article/pii/003807179500096W> Acesso em: 20 jan. 2012. doi: 10.1016/0038-0717(95)00096-W.

SAUTER, K.D. et al. Influência do lodo de esgoto doméstico e lodo de água sobre a mesofauna edáfica. Arquivos de Biologia e Tecnologia, Curitiba, v.39, n.4, p.745-750, 1996. Disponível em: $<$ http://bases. bireme.br/cgi-bin/wxislind.exe/iah/online/?IsisScript=iah/iah.xis $\&$ src $=$ google $\&$ base $=$ LILACS\&lang $=$ p\&nextAction $=$ lnk\&exprSe arc $\mathrm{h}=238880$ \&indexSearch=ID $>$. Acesso em: 17 jan. 2012. ID: 238880 .

SCHERER, E.E. et al. Atributos químicos do solo influenciados por sucessivas aplicações de dejetos suínos em áreas agrícolas de Santa Catarina. Revista Brasileira de Ciência do Solo, Viçosa, v.34, n.4, p.1375-1383, 2010. Disponível em: <http://www.scielo. $\mathrm{br} / \mathrm{scielo}$.php? pid $=\mathrm{S} 0100-06832010000400034 \& \mathrm{script}=\mathrm{sci}$ arttext>. Acesso em: 20 jan. 2012. doi: 10.1590/S010006832010000400034 .

SOCIEDADE BRASILEIRA DE CIÊNICA DO SOLO - SBCS. Manual de adubação e de calagem para os estados de Rio Grande do Sul e Santa Catarina. 10 ed. Porto Alegre, Sociedade Brasileira de Ciência do Solo - Núcleo Regional Sul 2004, 400p.

SILVA, R.F. da et al. Macrofauna invertebrada do solo sob diferentes sistemas de produção em Latossolo da Região do Cerrado. Pesquisa Agropecuária Brasileira, Brasília, v.41, p.697-704, 2006. Disponível em: <http://www.scielo.br/scielo.php?script=sci_ arttext\&pid=S0100-204X2006000400022\&lng=en $>$. Acesso em: 20 jan. 2012. doi: 10.1590/S0100-204X2006000400022.

TER BRAAK, C.J.F.; SMILAUER, P. CANOCO reference manual and user's guide to Canoco for Windows: software for canonical community ordination (version 4). New York: Microcomputer Power, 1998. 351p.

Ciência Rural, v.44, n.3, mar, 2014. 